\title{
ВОЗНИКНОВЕНИЕ, СТАНОВЛЕНИЕ И РАЗВИТИЕ АНАЛИТИЧЕСКОЙ ФИЛОСОФИИ ${ }^{1}$
}

\begin{abstract}
Я.В. Шрамко
Аналитическая философия является одним из наиболее влиятельных течений современной мировой философской мысли. Возникнув во второй половине XIX столетия в Австрии и Германии, в XX веке аналитическая философия заняла доминирующее положение, прежде всего, в академической философии стран англоязычного мира (Великобритании, Соединенных Штатов Америки, Канады, Австралии, Новой Зеландии), но также и во многих странах континентальной Европы (таких как Голландия, Швеция, Дания, Норвегия, Финляндия). Философы аналитического направления широко представлены на философских кафедрах университетов Германии, Франции, Италии и других европейских стран. Среди выдающихся деятелей аналитической философии следует, в первую очередь, назвать таких мыслителей как Готлоб Фреге (1848-1925), Бертран Рассел (1872-1970), Джордж Мур (1873-1958), Людвиг Витгенштейн (1889-1951), Рудольф Карнап (1891-1970) и Уиллард Куайн (1908-2002).

Важно иметь ввиду, что довольно трудно дать общую характеристику аналитической философии с точки зрения конкретных содержательных положений, которые разделялись бы всеми ее приверженцами. Речь идет о чрезвычайно разветвленном и многогранном философском движении, представители которого зачастую придерживаются самых разнообразных, иногда даже диаметрально противоположных позиций касательно тех или иных философских проблем и разделов. Аналитическая философия не образует и единой философской школы, как это имеет место, например, в случае с неокантианством, неотомизмом или феноменологией. Скорее, здесь можно выделить несколько самостоятельных школ

\footnotetext{
1 Эта статья, как и следующий за ней перевод работы Карнапа, Гана и Нейрата опубликованы также в журнале «Логос» (Москва), 2005, №2.
}

Актуальні проблеми духовності

(Відп. ред.: Я.В. Шрамко)

Кривий Ріг (2005), 185-194 
(таких как Венский кружок, Львовско-Варшавская школа логики, Кембриджская философия анализа и др.), которые вели и ведут между собой острые дискуссии, причем каждая из этих школ располагает собственным кругом рассматриваемых проблем и определенным набором типичных подходов к их решению.

В целом, то что действительно объединяет всех философов аналитического направления, находит свое выражение прежде всего в определенном способе постановки и исследования философских проблем. Иными словами, для аналитической философии характерен особый стиль $ф u-$ лософствования, приверженность которому отличает ее представителей от последователей других философских течений. Важнейшим элементом этого стиля является стремление рассматривать и решать собственно философские проблемы посредством философского анализа языка (этот подход ознаменовал собой так называемый лингвистический поворот в современной философии). В качестве второй особенности аналитической философии можно назвать активное использование методов и средств (в том числе, технических) современной логики и связь с определенного рода точной философской терминологией, которая вводится и определяется логически корректным образом. Еще одной неотъемлемой чертой аналитико-философского стиля является высокие требования к ясности и четкости аргументации, используемой для обоснования тех или иных философских положений. Аналитический философ скорее откажется от литературного своебразия и художественной элегантности своих произведений, чем от ясности, проверяемости и формальной (логической) корректности изложения ${ }^{2}$.

Аналитическая философия в значительной степени продолжает классические традиции философского анализа, лучшие образцы которого можно найти в работах Аристотеля, Декарта, Локка, Лейбница, Канта и других великих философов. В более близкой исторической ретроспективе, среди непосредственньх предшественников аналитической философии обычно называют Бернарда Больцано и Франца Брентано.

Бернард Больцано (1781-1848), чешский философ, логик и математик отстаивал в своих трудах (среди которых особенно следует отметить четырехтомную «Теорию науки», 1837) необходимость логической строгости при рассмотрении философских проблем, ясность и точность используемой при этом терминологии, важность тщательного анализа понятий. Тем самым, были заложены основы нового стиля философствования, для которого характерным является ориентация на анализ языка (в том числе, обыденного) и который в $\mathrm{XX}$ веке получил дальнейшее

${ }^{2}$ CM. Runggaldier, E. und Kanzian, C. Grundprobleme der analytischen Ontologie.Paderborn, München, Wien, Zürich: Verlag Ferdinand Schöningh, 1998, - S. 13-14. 
развитие в работах Мура, Витгенштейна и других представителей аналитической философии. Больцано выступил с критикой психологизма в логике, определяя логику как теорию высказываний, где высказывание понимается как «утверждение о том, что нечто существует или не существует ... независимо от того, было ли оно сформулировано в словах или просто пришло кому-нибудь в голову как мысль» ${ }^{3}$. Он сформулировал оригинальную дедуктивную систему, в которой предвосхитил многие идеи современной логики, в частности, понятия логического следования, логической выводимости и логической общезначимости. В своих исследованиях категории бесконечности Больцано утверждал объективность актуально бесконечного, явившись, по существу, предшественником теории актуально бесконечных множеств Георга Кантора.

Франц Брентано (1838-1917), немецкий философ и психолог, длительное время преподавал философию в Вене, где среди его учеников были Эдмунд Гуссерль, Алексиус Мейнонг, Казимир Твардовский. В своих исследованиях Брентано обратился к докантовской философии, прежде всего к идеям Аристотеля и средневековых схоластов, но также и английских эмпириков Нового времени (Локк, Беркли, Юм). Брентано особо подчеркивал научный статус философии и разрабатывал философский метод, нацеливающий на тщательный анализ конкретных проблем. По мнению Брентано, философ мало отличается от представителей других наук как и любой другой ученый он должен выбрать определенную проблему, сформулировать ее в предельно четких и ясных терминах и приложить все силы к ее решению. Для Брентано исходным пунктом философского исследования является анализ человеческого сознания. Основным признаком актов сознания, таких как представления, суждения и эмоции, является их интенциональность (направленность на предмет). В отличие от Канта, который определял суждение как связь представлений, Брентано проводит строгое различие между представлениями и суждениями, истолковывая последние в объективном, антипсихологистском духе, как акты утверждения или отрицания. Именно этим актам, и только им, могут быть приписаны такие характеристики как истинность или ложность. Эти идеи Брентано, и связанные с ними подходы к анализу языка, оказали непосредственное влияние на некоторых основоположников аналитической философии, в частности на этическую концепцию Дж. Мура. Кроме того, учение об интенциональности не только явилось важнейшим источником феноменологии Гуссерля, но и опосредованно, через теорию предметов Мейнонга, послужило одним из импульсов для разработки Расселом его теории дескрипций.

\footnotetext{
${ }^{3}$ Цит. по: Пассмор Дж. Сто лет философии.-М.: Прогресс-Традиция, 1998.-
} C. 431 . 
Переходя к вопросу о формировании собственно аналитической философии, необходимо отметить, что она имела сразу несколько исходных пунктов. Одним из таких исходных пунктов явилось философское творчество Готлоба Фреге, который считается основателем современной логики, создателем аналитической философии языка и одним из лидеров такого влиятельного направления в основаниях математики как логицизм. Вся профессиональная деятельность Фреге была связана с Йенским университетом, где он с 1874 по 1917 гг. преподавал математику, сначала в должности приват-доцента, а затем - экстраординарного и ординарного профессора. Фреге совершил подлинную революцию в логике, решительно отойдя от силлогистики Аристотеля и впервые сформулировав дедуктивную логическую систему в виде исчисления предикатов («Исчисление понятий», 1879). Он разработал и эффективно применил функциональный анализ языка, отказавшись от характерной для традиционной логики субъектно-предикатной структуры предложений. Для Фреге все выражения языка делятся на имена и функииональные выражения. Имена обозначают предметы, а функциональные выражения представляют предметные и логические функции (в зависимости от области их значений). Высказывания же рассматриваются как особого рода имена, значениями которых выступают два абстрактных объекта - «истина» и «ложь». Этот подход оказал в дальнейшем огромное влияние не только на логику и философию языка, но и на онтологические концепции аналитической философии, позволив сформулировать ряд жизнеспособных альтернатив аристотелевской субстанциально-атрибутной онтологии, обладающих, во многих отношениях, гораздо большей, по сравнению с последней, объясняющей силой. Фреге заложил основы логической семантики, проведя различие между смыслом и значением языковых выражений. В работах «Основания арифметики» $(1884)$ и «Основные законы арифметики» (т. I - 1893, т. II - 1903) им была развита грандиозная программа сведения основных понятий арифметики и всей математики к чисто логическим категориям. Позднее эта программа была в деталях разработана и исследована в фундаментальном труде Рассела и Уайтхеда «Principia Mathematica» (1910-1913), а также в работах Геделя, Карнапа, Куайна и других. Важную роль сыграла также борьба Фреге с психологизмом в логике.

Идеи Фреге были настолько новаторскими, что лишь немногие его современники смогли оценить их по достоинству. Еще меньше было тех, кто понял все их значение для развития мировой философской мысли. $\mathrm{K}$ счастью, среди этих немногих был Бертран Рассел, который, ознакомившись в 1900-1902 гг. с основными работами Фреге, в полной мере осознал важность содержащихся в них положений. Во-многом, именно благодаря усилиям Рассела, неустанно подчеркивавшим пионерскую роль Фреге в 
создании новой логики и философии, труды последнего получили распространение и, в конечном итоге, завоевали всеобщее признание. Особое место в истории науки занимает адресованное Фреге письмо Рассела, в котором тот сообщает об обнаруженном им в основаниях теории множеств противоречии, позднее получившем название «парадокс Рассела».

Однако было бы совершенно неверно рассматривать Рассела просто как одного из последователей Фреге. В идейном плане Рассел, скорее, явился последователем Мура, который в своей диссертации 1898 года («Природа суждения») объявил войну господствовавшей в то время в британских университетах идеалистической философии гегельянского типа (наибольшим влиянием здесь пользовалась система «абсолютного идеализма» Ф. Брэдли). Как Мур, так и Рассел получили философское образование в Кембридже, где позднее преподавали. В таких статьях как «Опровержение идеализма (1903)», «В защиту здравого смысла» (1925), «Доказательство внешнего мира» (1939) и др. Мур последовательно выступает против спекулятивного метода идеалистической метафизики и противопоставляет ему метод «понятийного анализа», целью которого должно быть выявление точного смысла языковых выражений, в том числе выражений обыденного языка. Рассел, по его собственному признанию, воспринял новую философию Мура как «великое освобождение» ${ }^{4}$, отвергнув идеалистический монизм Брэдли и характерный для него неогегельянский синтез. Рассел, по-видимому, был первым, кто четко обозначил свой философский метод, как «метод логического анализа».

Это «восстание против абсолютного идеализма» по существу послужило еще одной отправной точкой в развитии аналитической философии. В 30-х гг. ХХ столетия в Кембридже, в результате преподавательской и научной деятельности Мура и Рассела сложилась школа логического и языкового анализа к которой принадлежали Джон Уиздом, Сюзанна Стеббинг, Макс Блэк, Остин Дункан-Джонс и ряд других исследователей. В 1933 г. при непосредственном участии Стеббинг и Дункана-Джонса был основан журнал «Анализ», который и по сей день продолжает оставаться одним из наиболее влиятельньх изданий аналитико-философского направления. Основную задачу философии кембриджские аналитики видели в прояснении человеческого знания путем его логического и языкового анализа. Здесь следует также упомянуть Фрэнка Рамсея (1903-1929), талантливого кембриджского математика и философа, оставившего, несмотря на свою раннюю смерть, заметный след в современной логике.

Особую роль в становлении как Кембриджской школы, так и аналитической философии в целом сыграл Людвиг Витгенштейн (1889-1951)

\footnotetext{
${ }^{4}$ CM. Russell, B. My Philosophical Development. - London: Allen and Unwin, 1959.P. 54
} 
и его «Логико-философский трактат». Начиная с 1912 года Витгенштейн в течение пяти семестров изучал в Кембридже логику и математику под руководством Рассела. Отношения студента и преподавателя очень скоро приобрели характер тесного научного сотрудничества и переросли в регулярные дискуссии по самым разнообразным проблемам логики и философии. В ходе этих дискуссий обсуждались некоторые ключевые идеи, которые позднее лягли в основу «философии логического атомизма» Рассела, а также образовали ядро «Логико-философского трактата», созданного Витгенштейном к 1918 году и увидевшего свет в 1921 г. В соответствии с концепцией «Трактата» основным логическим элементом языка является высказывание. Высказывания призваны выражать (описывать) положения дел. Положения дел, которые действительно имеют место, суть факты; фактам соответствуют истинные высказывания ${ }^{5}$, мир же есть совокупность всех фактов. Высказывания состоят из выражений, каждое из которых (за исключением логических терминов) есть или далее неразложимое простое имя, или же образуется из простых имен. Имена обозначают предметы действительности. Таким образом, положения дел суть конфигурации предметов, а высказывания - комбинации имен. Логическая структура языка отражает метафизическую (категориальную) структуру мира.

Важное значение имела выдвинутая в «Трактате» программа критики метафизики и концепция философии как логического анализа языка. По мысли Витгенштейна, философия не может и не должна давать никакого знания о мире или о человеческом мышлении. Никаких метафизических истин не существует, поскольку не существует никакой особой метафизической природы вещей. Философы должны заниматься логическим анализом высказываний (утверждаемых конкретными науками) с целью их прояснения. Философия вносит вклад не в наше знание, а в наше понимание уже имеющегося знания.

Эта концепция не только интенсивно обсуждалась философами Кембриджской школы, но и оказала огромное влияние на группу исследователей, объединившихся в Вене вокруг Морица Шлика (1882-1936). В 1922 Шлик занял кафедру философии индуктивных наук ${ }^{6}$ в Венском университете. Вскоре после этого им был организован регулярный исследовательский семинар, в работе которого приняли участие представители различных наук, интересовавшиеся философскими проблемами. Объеди-

\footnotetext{
${ }^{5} \mathrm{~B}$ терминологии Рассела, факты - это то, что делает высказывания истинными или ложными.

${ }^{6}$ Полное название - «Кафедра философии, в особенности истории и теории индуктивных наук». Эта кафедра была создана в 1895 г. специально для Эрнста Маха, который занимал ее до 1901 г. Преемником Маха на этой кафедре (1902-1906) был выдающийся австрийский физик Людвиг Больцман.
} 
нение исследователей, сложившееся на основе этого семинара, получило название «Венский кружок». Активными участниками Венского кружка (кроме самого Шлика) были Рудольф Карнап, Отто Нейрат, Фридрих Вайсман, Филип Франк, Герберт Фейгль, Ганс Ган, Виктор Крафт, Курт Гедель и др. В 1929 г. вышло в свет программное произведение «Научное миропонимание - Венский кружок», написанное по инициативе Нейрата в соавторстве с Ганом и Карнапом, которое стало своеобразным манифестом всего движения, получившего также название «неопозитивизм» или «логический позитивизм» ${ }^{7}$. Члены Венского кружка полностью восприняли идеи «Трактата», связанные с преодолением традиционной метафизики и сведением задач философии к логическому анализу языка ${ }^{8}$ При этом, в качестве критерия осмысленности предложений ими был выдвинут принцип верификации, то есть эмпирической подтверждаемости всех научных высказываний и их сводимости к так называемым «протокольным предложениям» представляющим данные непосредственного опыта. В этом нашло свое выражение характерное для неопозитивизма стремление к последовательному эмпиризму. Кроме того, исследователи Венского кружка выдвинули и защищали идею «единой науки», настаивая на том, что не существует резких методологических и логических границ между различными отраслями научного знания, в частности, между естественными и гуманитарными науками.

Венский кружок тесно сотрудничал с действовашим в Берлине «Обществом научной философии» (Ганс Рейхенбах, Вальтер Дубислав, Курт Греллинг, Карл Гемпель). В 1930 г., при активном участии Рейхенбаха, был основан печатный орган Венского кружка - журнал «Познание» $(« \text { Erkenntnis» })^{9}$. Расцвет логического позитивизма пришелся на середину 30-х гг., но после смерти Шлика и присоединения в 1938 г. Австрии к нацистской Германии, когда большинство членов Венского кружка вынуждены были эмигрировать, естественное развитие этого движения было прервано.

Схожую судьбу имела и Львовско-Варшавская школа логики, основан-

\footnotetext{
${ }^{7} \mathrm{~B}$ отечественной литературе термин «неопозитивизм» иногда необосновано задействуется для огульного обозначения аналитической философии в целом (и вообе, любого научно ориентированного философского течения ХХ ст.). Такого рода расширительное (можно даже сказать, «ярлыковое») использование данного термина совершенно неправомерно как с исторической, так и с систематической точек зрения, и способно лишь вводить в заблуждение. Ни Рассел, ни Мур, ни многие другие аналитические философы никогда не были «неопозитивистами» и они, наверное, были бы немало удивлены, узнав, что кто-то пытается классифицировать их таким образом.

${ }^{8} \mathrm{C}$. Карнап P. Преодоление метафизики логическим анализом языка, Вестник Московского университета, сер. 7, Философия, №6, 1993.-С. 11-26.

9 До 1938 г. журнал издавался в Германии, затем - в Голландии. После оккупации Голландии в 1940 г. издание журнала было прекращено. В 1975 г. начал выходить новый «Erkenntnis», в качестве «международного журнала аналитической философии».
} 
ная Казимиром Твардовским (1866-1938), получившим в 1895 г. место профессора философии во Львовском университете. Среди выдающихся представителей этой школы следует выделить Яна Лукасевича, Станислава Лесневского, Казимира Айдукевича, Тадеуша Котарбинского, Альфреда Тарского. Особо плодотворным периодом в ее деятельности был промежуток между двумя мировыми войнами. Характерное для этой школы отрицательное отношение к иррационализму, использование разнообразных средств логического анализа для укрепления и обоснования рационалистической позиции оказало заметное влияние на последующие концепции и подходы аналитической философии. Представители Львовско-Варшавской школы внесли выдающийся вклад в развитие современной символической логики, логической семантики, теорию множеств, модальную и многозначную логику и многие другие области научного знания. Кроме того, они уделяли существенное внимание обоснованию возможности научной философии и стремились применять логический аппарат для повышения точности и эффективности философских исследований, развивая направление, которое может быть обозначено как «логическая философия» ${ }^{10}$.

В Великобритании после Второй мировой войны центр аналитического движения переместился из Кембриджа в Оксфорд. Решающую роль здесь сыграл Гильберт Райл (1900-1976), который был одним из основателей журнала «Анализ». В 1947 г. он сменил Мура на посту главного редактора журнала «Сознание» («Mind»), где оставался до 1971 г. В вышедшей в 1949 г. книге «Понятие сознания» Райл эффективно применил разработанный им метод «понятийного анализа» для исследования поставленной еще Декартом психофизической проблемы (проблемы соотношения души и тела). Решение этой и других философских проблем Райл видел на путях выявления понятийной путанницы, возникающей в результате систематических «категориальных ошибок», например, в результате трактовки предикатов, относящихся к сознанию (таких как «желать», «думать» и т.п.), как обычных, «физических» предикатов. Другой важнейшей фигурой Оксфордской послевоенной философии был Джон Остин (1911-1960), обозначавший свою философскую концепцию как «лингвистический феноменализм». Он концентрировал свои усилия на тщательном понятийном анализе обыденного языка, с целью выявления в обычном словоупотреблении самых разнообразных оттенков смысла (огромное значение для становления этого метода имела деятельность позднего Витгенштейна). Здесь, однако, нельзя вести речь о единой философской «школе» в точном смысле этого слова. Оксфордская аналитическая философия, к

\footnotetext{
${ }^{10} \mathrm{~B}$ этой связи примечательно называние журнала «Логика и логическая философия», который издается в Торуньском университете им. Николая Коперника (Польша).
} 
которой, кроме Райла и Остина, принадлежат Питер Стросон и ряд других крупных мыслителей (таких как Майкл Даммит), представляет собой, скорее, конгломерат различных, часто конкурирующих, концепций и подходов, которые лишь с большой натяжкой можно подвести под общее название «философия обыденного языка». Интересно отметить своего рода «реабилитацию» метафизики, которая прослеживается, например, в произведении Стросона «Индивиды» (1959), хотя бы даже под именем «дескриптивная метафизика», в задачу которой должно входить исследование наиболее общих категорий, определяющих структуру бытия.

В странах континентальной Европы аналитическая философия также постепенно увеличивает свое влияние. Особо сильные позиции завоевала она в Скандинавских странах, среди которых выделяется финская логико-философская школа, наиболее видными представителями которой признаны Георг Хенрик фон Вригт (1916-2003), и Яаакко Хинтикка.

Во второй половине XX ст. аналитическая философия интенсивно развивалась в Соединенных Штатах Америки. Важную роль сыграли здесь философы из Центральной Европы, вынужденные перед войной эмигрировать в США, где они заняли ключевые позиции на философских кафедрах некоторых наиболее известных университетов. Так, Карнап длительное время (с 1936 по 1961) преподавал в Гарварде, Принстоне, Чикагском и Калифорнийском университетах. Кроме того, в Соединенных Штатах имелась и собственная логико-аналитическая традиция, центром которой был Гарвардский университет, где работали основатель модальной логики Кларенс Ирвинг Льюис (1883-1964) и один из наиболее выдающихся американских философов XX ст. Уиллард Ван Орман Куайн, внесший существенный вклад как в логику и теорию множеств, так и в самые разнообразные области философии, такие как онтология, теория познания и философия языка. Американская аналитическая философия развивалась и развивается под сильным влиянием прагматизма, главным образом Чарльза Пирса (1839-1914), которого, наряду с Фреге и Расселом, считают одним из основателей современной логики. Среди американских аналитических философов второй половины века можно выделить Нельсона Гудмэна, Дональда Дэвидсона, Саула Крипке, Джона Сёрля и многих других. Следует также отметить деятельность американских логиков, таких как Алонзо Черч, Хаскелл Карри, Стефен Клини и других, превративших США в ведущую «логическую державу» мира.

Среди течений, которые непосредственно не относят себя к аналитической философии, но которые все же можно рассматривать как принадлежащие к аналитическому (рационалистическому) движению в широком смысле, необходимо, в первую очередь, назвать такое направление как «философия и методология науки». Центральной фигурой здесь является Карл Поппер (1902-1994) и его школа. Поппер родился в Вене, где 
жил и работал до своей эмиграции в 1937 г. в Новую Зеландию. После войны он занял место профессора по логике и научному методу в Лондонской школе экономики и политических наук. Поппер противопоставил свою методологическую концепцию, которую он называл «критическим рационализмом», методологии Венского кружка, с представителями которого он вел острые дискуссии. В качестве основных проблем философии науки он выделял проблему научного метода (логики науки) и проблему демаркации (проведения четкой границы между наукой и тем, что ею не является). Поппер отверг принцип верификации как критерий научности, и противопоставил ему свой принцип фальсификации (принципиальной опровержимости подлинно научного знания). Он также явился последователем Юма, доказывая невозможность индуктивной логики, и вообще индукции как действительно научного метода. Согласно Попперу, рост научного знания осуществляется в результате применения гипотетикодедуктивного метода, через формулировку проблем, выдвижение гипотез и их последующую проверку, с целью решения сформулированных проблем. Философские интерессы Поппера не ограничивались логикой и методологией науки, а включали в себя широкий круг философских проблем человека и общества. Важное значение для современной социальной и политической философии имеет разработанная Поппером концепция открытого общества, представленная, прежде всего, в книге «Открытое общество и его враги» (1945) - одном из наиболее значительных социально-философских произведений ХХ ст.

Если мы бросим взгляд на современное состояние аналитической философии, то, прежде всего, должны будем отметить имеющееся здесь чрезвычайное многообразие. Исследования в области аналитической философии охватывают практически все традиционные разделы, такие как онтология, теория познания, философия языка, социальная философия, этика, философия религии и многие другие, причем по каждому из этих разделов существует множество самых разных подходов, концепций и точек зрения. Это разнообразие даже дает некоторым исследователям повод усомниться в том, что в настоящее время вообще можно вести речь об аналитической философии как о едином философском направлении ${ }^{11}$. Тем не менее, представляется, что указанное многообразие может быть истолковано и как сильная сторона аналитического движения, которая обеспечивает его широту и позволяет включать в его рамки различные философские концепции, при условии, что они соответствуют отмеченным в начале данной статьи стандартам (критериям), предъявляемым к философско-аналитическим исследованиям .

\footnotetext{
${ }^{11}$ Так, например, Ричард Рорти утверждает: «Я не думаю, что все еще существует что-либо, идентифицируемое как ,аналитическая философия“» (Rorty, R. Philosophy and the Mirror of Nature. - Oxford: Basil Blackwell, 1980, - P. 172).
} 